Federal Reserve Bank of Minneapolis

Research Department

\title{
The Time Consistency of Monetary and Fiscal Policies
}

\author{
Fernando Alvarez, Patrick J. Kehoe, \\ and Pablo Neumeyer*
}

Working Paper 616

April 2002

\begin{abstract}
Are optimal monetary and fiscal policies time consistent in a monetary economy? Yes, but if and only if under commitment the Friedman rule of setting nominal interest rates to zero is optimal. This result is of applied interest because the Friedman rule is optimal for the standard preferences used in applied work, those consistent with the growth facts.
\end{abstract}

\footnotetext{
*Alvarez, University of Chicago, Universidad T. Di Tella, and NBER; Kehoe, Federal Reserve Bank of Minneapolis, University of Minnesota, and NBER; Pablo Neumeyer, Universidad T. Di Tella and CONICET. Alvarez and Neumeyer thank Agencia de Promoción Científica y Tecnológica for financial support. Kehoe thanks the NSF for financial support. The views expressed herein are those of the authors and not necessarily those of the Federal Reserve Bank of Minneapolis or the Federal Reserve System.
} 
A classic issue in macroeconomics is whether or not optimal monetary and fiscal policies are time consistent. In a monetary economy, Calvo (1978) shows that the incentive for the government to inflate away its nominal liabilities leads to a time consistency problem for optimal policies. (See also Auernheimer 1974.) In a real economy, Lucas and Stokey (1983) show that the incentive for the government to devalue its real debt typically also leads to a time consistency problem for optimal policies. Lucas and Stokey (1983) have shown that, with a carefully chosen maturity structure for real government debt, optimal policies can be made time consistent in a real economy. But they have argued that the analogous result does not hold for a monetary economy with real and nominal debt. Here we show that it does. For a class of monetary economies typically used in applied work, we show that optimal policies are time consistent, but if and only if under commitment the Friedman rule of setting the nominal interest rate to zero is optimal.

The model we use is an infinite horizon model with money in the utility function of the representative consumer. In this model, the government has access to nominal and real debt of all maturities and must finance a given stream of government expenditures with a combination of consumption taxes and seigniorage. Following Lucas and Stokey (1983), we abstract from the well-understood problems arising from capital taxation by not including any kind of capital.

Our approach to the issue of time consistency is basically that of Lucas and Stokey (1983). To establish our benchmark for optimal policy, we begin by solving for Ramsey policies, namely, the optimal policies in an environment where the initial government has a commitment technology that binds the actions of future governments. In this environment, therefore, the initial government chooses policy once and for all. Ramsey policies here consist of sequences of consumption taxes and money supplies.

We then turn to the environment of interest in which no such commitment technology exists. In it each government inherits a maturity structure of nominal and real debt. Each such government then decides on the current setting for the consumption tax and the money supply, as well as the maturity structure of nominal and real debt that its successor will inherit. We ask whether a maturity structure of government debt can be chosen so that all governments carry out 
the Ramsey policies. If it can, we call the Ramsey policies time consistent.

It turns out that if the Ramsey policies are to be time consistent, then the structure of the nominal bonds that a government in period $t$ leaves to its successor in period $t+1$ must be severely restricted. One of these restrictions is well understood: the present value of nominal claims must be zero. If this present value is positive, then the successor in period $t+1$ will inflate the nominal claims away by setting the price level in period $t+1$ to be very large, while if the present value is negative, the successor will make its claims on the public large by setting the price level in period $t+1$ to be very low.

A critical step in our analysis is uncovering some more subtle restrictions: if the Friedman rule does not hold in some period $t$, then the present value of nominal bonds from that period on must be zero. This restriction on nominal bonds restricts the initial government's means of influencing the choices of its successor to, primarily, real bonds. In general, the government in any period is so restricted in influencing its successor that it cannot induce its successor to carry out the continuation of its plan. In particular, if the Friedman rule does not hold, then no matter what structure the government sets for real bonds in period $t$, the successor government has an incentive to deviate from the continuation of the period $t$ allocations either by altering taxes in a way that devalues the real debt or by changing the amount of seigniorage raised.

When the Friedman rule holds, consumers are satiated with money balances and no seignorage is raised - as if money has disappeared - so that the economy is equivalent to a real economy. In this economy, the government in any period can induce its successor to carry out its plan by carefully choosing a maturity structure of the real bonds and by choosing the maturity structure of nominal bonds so that the value of nominal liabilities is zero in each period.

We argue that economies for which the Friedman rule is optimal and hence those for which optimal policies are time consistent are both of applied interest. This is because the preferences most frequently used in the applied literature are those consistent with the growth facts, and we show that the Friedman rule is optimal for essentially all such preferences.

We develop a useful analogy between our monetary economy and a real economy similar to 
that of Lucas and Stokey (1983). Our real economy has leisure and two types of consumption goods. As is well known, there is a close analogy between the optimality of uniform commodity taxation in a real economy and the optimality of the Friedman rule in a monetary economy. We show that this close analogy extends to the time consistency of optimal policies.

In our monetary economy, the incentive to inflate away nominal debt endogenously restricts the government to using basically only one type of debt, real debt, to influence its successors. In the real economy, we imitate that endogenous restriction on debt by exogenously imposing the restriction that the government has access to only one real bond of all maturities. We show that with this restriction, optimal policies are time consistent if and only if uniform taxes are optimal - that is, if in each period, taxing the two consumption goods at the same rate is optimal.

To understand this result for the real economy, we consider a $T$-period economy and show that, in general, there is no way to choose the $T$ real government bonds to ensure time consistency of an optimal plan for setting the $2 T$ tax rates (two tax rates in each of $T$ periods). When uniform commodity taxation is optimal, there are, in essence, only $T$ such tax rates. Then the $T$ government bonds can be chosen in a way that ensures that deviating from the original plan is not optimal.

The analog in the monetary economy is that there is typically no way to choose the $T$ real government bonds to ensure the time consistency of an optimal plan for setting $2 T$ tax rates in each of $T$ periods (the consumption tax and a tax on real balances, namely, the nominal interest rate). When the Friedman rule is optimal, there are, in essence, only $T$ such tax rates, the consumption taxes, and the $T$ real government bonds can be chosen to ensure that deviating from the original plan is not optimal.

We follow the original approach to time consistency used by Calvo (1978) and Lucas and Stokey (1983). In Appendix C, we relate this approach to the approaches of sustainable plans used by Chari and Kehoe (1992) and credible policies used by Stokey (1991). Those approaches explicitly build the government's lack of commitment into the environment with an equilibrium concept in which governments explicitly think through how their choices of debt influence their 
successors' choices. We show in Appendix C that optimal policies are time consistent if and only if they are supportable as a Markov sustainable equilibrium.

Our study is related to that of Persson, Persson, and Svensson (1987). They argue that with a sufficiently rich term structure of both nominal and real government debt, optimal policies can be made time consistent regardless of whether or not the Friedman rule is satisfied. Unfortunately, their result is not true. Calvo and Obstfeld (1990) sketch a variational argument which suggests that the solution proposed by Persson, Persson, and Svensson (1987) is not time consistent. Calvo and Obstfeld conjecture that the mistake of those researchers is that their proposed solution violates the second-order conditions. We formalize the Calvo-Obstfeld conjecture here and precisely characterize the conditions under which it applies. We find that the mistake of Persson, Persson, and Svensson has less to do with second-order conditions and more to do with a lack of attention to subtle corners in the price level which lead to the additional restrictions on the nominal bonds that a government can leave to its successor. More importantly, unlike Calvo and Obstfeld, we conclude that Ramsey policies are time consistent for an interesting set of economies.

\section{The Ramsey problem and the Friedman rule}

We start by constructing our economy, describing its Ramsey problem, and demonstrating the conditions under which the Friedman rule is optimal.

\section{The Economy}

Consider a monetary economy with money, nominal government debt, and real government debt. Time is discrete. The resource constraint is given by

$$
c_{t}+g_{t}=l_{t}
$$

where $c_{t}, g_{t}$, and $l_{t}$ denote consumption, government spending, and labor in time period $t$. Throughout, the sequence of government spending is exogenously given.

In this economy, consumers have preferences over sequences of consumption $c_{t}$, real money balances $M_{t} / p_{t}$, and labor $l_{t}$ given by

$$
\sum_{t=0}^{\infty} \beta^{t} U\left(c_{t}, M_{t} / p_{t}, l_{t}\right)
$$


with the discount factor $0<\beta<1$. Here $M_{t}$ is (end-of-period) nominal money balances and $p_{t}$ is the nominal price level, and we let $m_{t}=M_{t} / p_{t}$ denote real money balances. We assume that the period utility function $U(c, m, l)$ is concave, twice continuously differentiable, increasing in $c$, and decreasing in $l$. We also assume that consumers are satiated at a finite level of real balances, so that for each value of $c$ and $l$, there is a finite level of $m$ such that $U_{m}(c, m, l)=0$, where here and throughout, we denote partial derivatives by $U_{m}, U_{m m}$, and so on.

In terms of assets, we assume there exist both nominal and real bonds for every maturity. For the nominal bonds, for each period $t$ and $s$ with $t \leq s$, we let $Q_{t, s}$ denote the price of one dollar in period $s$ in units of dollars in period $t$, and we let $B_{t, s}$ denote the number of such nominal claims. Similarly, for the real bonds, we let $q_{t, s}$ denote the price of one unit of consumption in period $s$ in units of consumption in period $t$ and let $b_{t, s}$ denote the number of such real bonds. We let $B_{t}=\left(B_{t, t+1}, B_{t, t+2}, \ldots\right)$ denote the vector of nominal bonds purchased by consumers in $t$ which pay off $B_{t, s}$ in $s$ for all $s \geq t+1$. We use similar notation for the real bonds $b_{t}$ and the nominal and real debt prices $Q_{t}$ and $q_{t}$. For later use, note that arbitrage among these bonds implies that for all $t \leq r \leq s$, their prices satisfy $Q_{t, s}=Q_{t, r} Q_{r, s}, q_{t, s}=q_{t, r} q_{r, s}$, and $Q_{t, s}=q_{t, s} p_{t} / p_{s}$. By convention, $Q_{t, t}=1$ and $q_{t, t}=1$.

Each consumer's sequence of budget constraints in period $t$ can be written as

$$
\begin{aligned}
& p_{t}\left(1+\tau_{t}\right) c_{t}+M_{t}+\sum_{s=t+1}^{\infty} Q_{t, s} B_{t, s}+p_{t} \sum_{s=t+1}^{\infty} q_{t, s} b_{t, s} \\
= & p_{t} l_{t}+M_{t-1}+\sum_{s=t}^{\infty} Q_{t, s} B_{t-1, s}+p_{t} \sum_{s=t}^{\infty} q_{t, s} b_{t-1, s} .
\end{aligned}
$$

Thus, in period $t$, each consumer has a nominal wage income of $p_{t} l_{t}$, nominal money balances $M_{t-1}$, a vector of nominal bonds $B_{t-1}$, and a vector of real bonds $b_{t-1}$. Consumers purchase consumption $c_{t}$, new money balances $M_{t}$, and new vectors of nominal bonds $B_{t}$ and real bonds $b_{t}$. Purchases of consumption are taxed at the rate $\tau_{t}$. In period 0 , consumers have initial money balances $M_{-1}$, together with initial vectors of nominal and real bonds $B_{-1}$ and $b_{-1}$. We assume that in each period the real values of both nominal and real debt purchased are bounded by some arbitrarily 
large constants.

It is convenient to work with the consumers' problem in period 0 form. The sequence of budget constraints (3) can be collapsed to the period 0 budget constraint:

$$
\begin{aligned}
& \sum_{t=0}^{\infty} q_{0, t}\left[\left(1+\tau_{t}\right) c_{t}+\left(1-Q_{t, t+1}\right) m_{t}\right] \\
= & \sum_{t=0}^{\infty} q_{0, t} l_{t}+\frac{M_{-1}}{p_{0}}+\sum_{t=0}^{\infty} Q_{0, t} \frac{B_{-1, t}}{p_{0}}+\sum_{t=0}^{\infty} q_{0, t} b_{-1, t} .
\end{aligned}
$$

We can interpret the term $\left(1-Q_{t, t+1}\right) m_{t}$ as the effective tax on real balances paid by households. Notice that this effective tax is positive when $Q_{t, t+1}<1$ and zero when $Q_{t, t+1}=1$. The consumers' problem in period 0 is to choose sequences of consumption, real balances, and leisure to maximize (2) subject to (4).

The government's sequence of budget constraints in period $t$ is

$$
\begin{aligned}
& \sum_{s=t+1}^{\infty} Q_{t, s} B_{t, s}+p_{t} \sum_{s=t+1}^{\infty} q_{t, s} b_{t, s} \\
= & \sum_{s=t}^{\infty} Q_{t, s} B_{t-1, s}+p_{t} \sum_{s=t}^{\infty} q_{t, s} b_{t-1, s}+p_{t} g_{t}-\left(M_{t}-M_{t-1}\right)-p_{t} \tau_{t} c_{t} .
\end{aligned}
$$

In period $t$, the government inherits the nominal money $M_{t-1}$, the nominal debt vector $B_{t-1}$, and the real debt vector $b_{t-1}$. To finance government spending $g_{t}$, the government collects consumption taxes $\tau_{t} c_{t}$ and issues new money $M_{t}$, new nominal debt $B_{t}$, and new real debt $b_{t}$. Using the resource constraint and the consumers' period 0 budget constraint, we can collapse the government's sequence of constraints into its period 0 budget constraint:

$$
\sum_{t=0}^{\infty} q_{0, t}\left[\tau_{t} c_{t}+\left(1-Q_{t, t+1}\right) m_{t}-g_{t}\right]=\frac{M_{-1}}{p_{0}}+\sum_{t=0}^{\infty} Q_{0, s} \frac{B_{-1, s}}{p_{0}}+\sum_{t=0}^{\infty} q_{0, t} b_{-1, t} .
$$

We find it convenient to use the notation ${ }_{t} c=\left(c_{t}, c_{t+1}, \ldots\right)$ for consumption and similar notation for real balances, labor, prices, and taxes. For given initial conditions $M_{-1}, B_{-1}$, and $b_{-1}$, then, a competitive equilibrium is a collection of sequences of consumption, real balances, and labor $\left({ }_{0} c,{ }_{0} m,{ }_{0} l\right)$ together with sequences of prices $\left({ }_{0} p, Q_{0}, q_{0}\right)$ and taxes ${ }_{0} \tau$ that satisfy the resource constraint and consumer maximization in period 0 . The government budget constraint is 
then implied.

In any equilibrium, nominal interest rates are nonnegative, so that the one-period bond price $Q_{t, t+1}=1+U_{m t} / U_{l t} \leq 1$. Since $U_{l t} \leq 0$, for interest rates to be nonnegative, the marginal utility of money must satisfy

$$
U_{m t} \geq 0
$$

which we refer to as the nonnegative interest rate constraint. It is easy to show that the allocations in a competitive equilibrium are characterized by three simple conditions: the resource constraint (1), the nonnegative interest rate constraint (7), and the implementability constraint, the last of which is

$$
\sum_{t=0}^{\infty} \beta^{t} R\left(c_{t}, m_{t}, l_{t}\right)=-\frac{U_{l 0}}{p_{0}}\left(M_{-1}+\sum_{t=0}^{\infty} Q_{0, t} B_{-1, t}\right)-\sum_{t=0}^{\infty} \beta^{t} U_{l t} b_{-1, t},
$$

where $R\left(c_{t}, m_{t}, l_{t}\right)=c_{t} U_{c t}+m_{t} U_{m t}+l_{t} U_{l_{t}}$ is the government surplus $\tau_{t} c_{t}+\left(1-Q_{t, t+1}\right) m_{t}-g_{t}$ expressed in marginal utility units and $Q_{0, t}=\prod_{s=0}^{t-1}\left[1+\left(U_{m s} / U_{l s}\right)\right]$. This implementability constraint should be thought of as the period 0 budget constraint of either the consumers or the government, where the consumer's first-order conditions have been used to substitute out prices and policies. The following lemma is standard and is included without a proof.

Lemma 1. For some given initial conditions, $M_{-1}, B_{-1}$, and $b_{-1}$, the consumption, real balance, and labor allocations together with the price $p_{0}$ of a period 0 competitive equilibrium necessarily satisfy the resource constraint, the nonnegative interest rate constraint, and the implementability constraint. Furthermore, for any such allocations and a price $p_{0}$ that satisfy these constraints for some given initial conditions, $M_{-1}, B_{-1}$, and $b_{-1}$, we can construct nominal money supplies, prices, and nominal and real debt prices such that these allocations and prices constitute a period 0 competitive equilibrium.

\section{The Ramsey Problem}

Consider now the Ramsey problem in period 0 , given $M_{-1}, B_{-1}$, and $b_{-1}$, which is to choose ${ }_{0} c,{ }_{0} m,{ }_{0} l$, and $p_{0}$ to solve

$$
\max \sum_{t=0}^{\infty} \beta^{t} U\left(c_{t}, m_{t}, l_{t}\right)
$$


subject to the resource constraint (1), the nonnegative interest rate constraint (7), and the implementability constraints (8).

Our results will depend critically on whether or not the allocations that solve this problem satisfy the Friedman rule in that

$$
Q_{t, t+1}=1, \text { for all } t
$$

so that nominal interest rates are zero in every period. Since $Q_{t, t+1}=1+\left(U_{m t} / U_{l t}\right)$ and $U_{l t}<0$, the Friedman rule holds if and only if

$$
U_{m t}=0 \text {, for all } t \text {. }
$$

We now discuss the initial conditions for both nominal and real government debt that we choose for the Ramsey problem. To make the problem interesting, we want initial conditions for which distortionary taxes are necessary. A sufficient condition for this to be true is that in each period $t$, the sum of government spending and the real initial debt maturing in period $t$ is positive. That is,

$$
g_{t}+b_{-1, t}>0
$$

for all $t$. We assume that (12) holds throughout.

The solution to the Ramsey problem depends critically on the structure of the value of the government's initial nominal liabilities as well, namely, the initial money supply $M_{-1}$ and the vector of initial nominal debt $B_{-1}$ through the term

$$
-\frac{U_{l 0}}{p_{0}}\left(M_{-1}+\sum_{t=0}^{\infty} Q_{0, t} B_{-1, t}\right)
$$

in the implementability constraint. The term $\left[M_{-1}+\sum_{t=0}^{\infty} Q_{0, t} B_{-1, t}\right]$ is the present value of the government's nominal liabilities in units of dollars in period 0 . Dividing by $p_{0}$ converts this value into period 0 consumption good units, and multiplying by $-U_{l 0}$ converts the result into units of period 0 utility.

We assume that initial nominal government liabilities are all zero, in that

$$
M_{-1}+B_{-1,0}=0 \text { and } B_{-1, t}=0, \text { for all } t \geq 1 .
$$


Under (14) the present value of nominal liabilities in (13) is identically equal to zero and the Ramsey problem is independent of $p_{0}$.

\section{The Friedman Rule}

In the next section, we will show that the Ramsey problem is time consistent if and only if the Friedman rule is optimal in each period. Here we establish sufficient conditions for the Friedman rule to be optimal in each period in an economy that satisfies (14). If we let $\gamma_{t}, \eta_{t}$, and $\lambda_{0}$ denote the multipliers on the resource constraint, (1), the nonnegative interest rate constraint (7), and the implementability constraint (8) and we assume (14), then for $t \geq 1$, the first-order conditions for $c_{t}, m_{t}$, and $l_{t}$ are

$$
\begin{aligned}
& U_{c t}+\lambda_{0}\left(R_{c t}+b_{-1, t} U_{l c t}\right)+\eta_{t} U_{m c t}+\frac{\lambda_{0} U_{l 0}}{p_{0}} Q_{c t, t+1} \sum_{s=t+1}^{\infty} Q_{t+1, s} B_{-1 s}=\gamma_{t} \\
& U_{l t}+\lambda_{0}\left(R_{l t}+b_{-1, t} U_{l l t}\right)+\eta_{t} U_{m l t}+\frac{\lambda_{0} U_{l 0}}{p_{0}} Q_{l t, t+1} \sum_{s=t+1}^{\infty} Q_{t+1, s} B_{-1 s}=-\gamma_{t} \\
& U_{m t}+\lambda_{0}\left(R_{m t}+b_{-1, t} U_{l m t}\right)+\eta_{t} U_{m m t}+\frac{\lambda_{0} U_{l 0}}{p_{0}} Q_{m t, t+1} \sum_{s=t+1}^{\infty} Q_{t+1, s} B_{-1 s}=0,
\end{aligned}
$$

where $Q_{t, s}=\Pi_{r=t}^{s}\left[1+\left(U_{m r} / U_{l r}\right)\right]$ and where $Q_{i t, t+1}$ are the derivatives of $1+\left(U_{m t} / U_{l t}\right)$ with respect to $i=c, m, l$. For $t=0$, we add $U_{l c 0} \lambda_{0}\left[M_{-1}+\sum_{t=0}^{\infty} Q_{0, t} B_{-1 t}\right] / p_{0}$ to the left side of (15), and we add analogous terms for (16) and (17).

We can use these first-order conditions to establish circumstances under which the Friedman rule is optimal. Consider an economy with preferences that are separable and homothetic in that

$$
U(c, m, l)=u(w(c, m), l)
$$

where the function $w$ is homothetic in $c$ and $m$ and for which initial nominal government liabilities are all zero. Preferences that satisfy (18) include commonly used preferences in monetary models like $U=w(c, m)^{1-\sigma} v(l) /(1-\sigma)$, where $w$ is homogeneous of degree one. Such preferences are consistent with some basic facts of economic growth: hours worked per person have been approximately constant, and consumption, real balances, and income have grown at approximately the 
same rate. (See Lucas 2000 b.) In particular, the utility function must be homothetic in the sense that

$$
\frac{U_{m}(\alpha c, \alpha m, l)}{U_{c}(\alpha c, \alpha m, l)}=\frac{U_{m}(c, m, l)}{U_{c}(c, m, l)}
$$

for any $\alpha$, which is clearly satisfied by (18). The following proposition, proved in Appendix A, is related to but not covered by the results of Chari, Christiano, and Kehoe (1996).

Proposition 1. If preferences are separable and homothetic, so that (18) holds, and the initial nominal government liabilities are all zero, so that (14) holds, then the Friedman rule is optimal.

As we have noted, the preferences we have assumed in Proposition 1 are consistent with the balanced growth facts. We show that, essentially, if preferences are consistent with balanced growth, then the Friedman rule is optimal. Define the satiation level of money $m^{*}(c, l)$ to be the smallest level of real balances for which its marginal utility is zero; that is,

$$
m^{*}(c, l)=\min \left\{m: U_{m}(c, m, l)=0\right\} .
$$

Proposition 2. Assume that initial nominal government liabilities are all zero in that (14) holds that $U_{m l} \geq 0$ whenever $U_{m}=0$. If preferences are consistent with balanced growth in the sense of (19), then the Friedman rule solves the Ramsey problem.

We prove this proposition in Appendix A. The proposition is related to, but not covered by, the results of Correia and Teles (1999). In the proof, we show that if $U_{m l} \geq 0$ and preferences are consistent with balanced growth, then we can construct a feasible allocation and nonnegative multipliers that satisfy the first-order conditions as well as the implementability condition.

Note that preferences such as $U=c^{1-\sigma} v(m / c, l) /(1-\sigma)$ satisfy balanced growth, but do not satisfy the Friedman rule if $v_{12} / v_{11}>0$. For such preferences, $U_{m l}$ is negative at $U_{m}=0$.

\section{Endogenous Restrictions on Nominal Debt Left to Future Governments}

In the next section we carefully define our notion of time consistency. The intuitive idea is that for each period $t$, the period $t$ government must be able to leave vectors of real and nominal debts to its successor, the period $t+1$ government, such that the successor has the incentive to 
carry out the continuation of the plan of the period $t$ government. Here we show that for many vectors of nominal debt that could be left to the successor at $t+1$, there will be no interior solution to the successor's problem. Under our assumptions the Ramsey problem in period 0 will entail an interior solution for $p_{t+1}$ for all $t$. Thus, for any vector of nominal debt left to a government at $t+1$ to be part of a time consistent solution, it must be that, having inherited such a vector, the government chooses an interior solution for the price level $p_{t+1}$.

In Lemma 2 we show that the necessary restrictions for an interior solution to exist are that if the Friedman rule does not hold in some period, then from that period on the present value of nominal debt must be zero. Although useful in the analysis of time consistency, the lemma is simply about the type of restrictions initial nominal debt vectors must satisfy in order for an interior solution to a Ramsey problem to exist.

For notational simplicity, we focus on the restrictions the nominal debt inherited by the period 0 government must satisfy, and it is clear that the same logic applies to any period $t$. (Of course, for the period 0 government the inherited debt is part of the environment, while for any period $t$ government with $t \geq 1$ the inherited debt is part of the endogenous construction of a potentially time consistent plan. Regardless, the lemma applies to any period $t \geq 0$.) Clearly, for the Ramsey problem in period 0 to have an interior solution for $p_{0}$, namely, $0<p_{0}<\infty, M_{-1}$ and $B_{-1}$ must satisfy the condition

$$
M_{-1}+\sum_{t=0}^{\infty} Q_{0, t} B_{-1, t}=0
$$

This condition, however, is not enough to eliminate the nominal forces that lead to either no solution or a corner solution. We show that the following stronger conditions are necessary. If in some period $s$, the Friedman rule does not hold, so that $Q_{s, s+1}<1$, then the present value of government debt from period $s+1$ on must be zero, so that

$$
0=\sum_{t=s+1}^{\infty} Q_{1, t} B_{-1, t}=Q_{1 s} Q_{s, s+1} \sum_{t=s}^{\infty} Q_{s+1, t} B_{-1, t}
$$

We will assume there is some period - say, $r$ - in which consumption taxes are being levied so that $-U_{c r} / U_{l r}=1+\tau_{r}>1$. We will assume that in this period $r$, the second derivatives satisfy the 
conditions

$$
U_{m m}+U_{l m}<0 \text { if } U_{m}>0, U_{l l}+U_{l c} \geq 0, \text { and } U_{m c}+U_{m l} \geq 0 .
$$

Lemma 2 determines restrictions that inherited nominal debt must satisfy for an interior solution to that government's problem to exist.

The proof of this lemma is rather intricate and is related to the informal variational argument suggested by Calvo and Obstfeld (1990). The proof proceeds by contradiction. We suppose that at the solution the Friedman rule does not hold and that the present value of the nominal government liabilities from period 0 on is zero but the present value from period $t$ on is not zero. We then show that no such solution can exist by constructing an allocation that gives higher utility. In the construction we perturb the original allocation in two steps. The first step is a small variation in nominal interest rates, which may entail lowering them. This variation will make the present value from period 0 on strictly negative, so that the consumers owe the government some nominal amount. Once the consumers owe the government any nominal amount, say, one dollar, the government can raise any amount of revenues it desires by making the initial price level low enough. The second step is to reduce taxes and thus increase welfare, while keeping the nominal interest rates unchanged from the first step to ensure that the consumers owe the government some nominal amount.

Lemma 2. Assume that an interior solution to the Ramsey problem in period 0 with $0<p_{0}<\infty$ exists, that there is some period $s$ in which the Friedman rule does not hold, that there is some period $r$ in which consumption taxes are levied, and that in period $r$ the conditions (22) hold. Then the value of initial nominal government debt from $s+1$ on is zero, so that (21) holds.

Proof. We establish the result by showing that if the assumptions of the lemma hold and (21) does not hold, then we can perturb the allocations and increase utility.

We construct the perturbation in two steps. In the first step, we perturb the allocation in order to make the present value of the government's nominal liabilities negative and then lower the initial price level. If $Q_{s, s+1}<1$ and (20) holds but (21) does not hold, then we can make 
the present value of the government's nominal liabilities negative by a small change in $Q_{s, s+1}$. This change, which may entail either raising or lowering $Q_{s, s+1}$, is feasible since the Friedman rule does not hold at $s$. We change $c_{s}, m_{s}$, and $l_{s}$ in a way that satisfies the resource constraint and produces the desired change in $Q_{s, s+1}$. Then, by lowering the initial price level $p_{0}$, we can generate any desired level of real assets for the government.

In the second step of the perturbation, we lower the taxes in the period that we have hypothesized has positive taxes, namely, period $r$, in a way that raises utility in that period, satisfies the resource constraint, and holds fixed the $Q_{r, r+1}$, so that we know that the perturbed allocation still implies a strictly negative value for nominal government liabilities so that the first step of the perturbation still works. To that end, note that positive taxes in period $r$ imply that $-U_{l r}<U_{c r}$. Since $U_{m r} \geq 0$, we can increase $c_{r}$ and $m_{r}$ and decrease $l_{r}$ in a way that keeps $Q_{r, r+1}$ constant, satisfies the resource constraint, and increases utility in period $r$. Clearly, by the implicit function theorem, for a fixed $Q_{r, r+1}$ and $g_{r}$, functions $m(c)$ and $l(c)$ exist such that $c, m(c)$, and $l(c)$ satisfy

$$
U_{m}(c, m(c), l(c))+\left(1-Q_{r, r+1}\right) U_{l}(c, m(c), l(c))=0
$$

and $c+g_{r}=l(c)$. These functions satisfy $l^{\prime}(c)=1$, and if $U_{m}>0$, then

$$
m^{\prime}(c)=-\left[\frac{U_{m c}+U_{m l}+\left(1-Q_{r, r+1}\right)\left(U_{l l}+U_{l c}\right)}{U_{m m}+\left(1-Q_{r, r+1}\right) U_{l m}}\right],
$$

which is nonnegative under our assumptions on second derivatives. (Note that since $U_{m m} \leq 0$, the denominator in $(24)$ is nonpositive even if $U_{l m}>0$, because $U_{m m}+U_{l m}<0$ and $1-Q_{r, r+1} \leq 1$.)

If $U_{m}>0$, then increasing $c$, and thus changing $m$ and $l$ by $m^{\prime}(c)$ and $l^{\prime}(c)$, leads utility in period $r$ to change by $U_{c}+U_{l}+U_{m} m^{\prime}(c)$, which is strictly positive since by assumption at $r$, $-U_{l}<U_{c}, U_{m} \geq 0$, and $m^{\prime}(c) \geq 0$.

If $U_{m}=0$, it must be that $Q_{r, r+1}=1$. Consider now the case where $U_{m m}<0$. To ensure that $(23)$ holds, it is enough to let $m^{\prime}(c)=-\left(U_{m c}+U_{m l}\right) / U_{m m}>0$. In this case the resulting change in utility in period $r$ is $U_{c}+U_{l}>0$. If at some point $U_{m}=0$ and $U_{m m}=0$, by concavity it must be that $U_{m l}=U_{c m}=0$ at this point as well. (To see this, note that if $U_{m}=0$ at some 
point $m$, then since $U$ is weakly increasing in $m, U_{m}=0$ at all points $m^{\prime} \geq m$. Thus, since $U$ is twice continuously differentiable, $U_{m m}=0$. To see that $U_{m c}=0$, note that by concavity $U_{c c} U_{m m}-U_{m c}^{2} \geq 0$, so $U_{m c}=0$. A similar argument applies for $U_{m l}$.) Hence a small change in $c$ and $l$ does not change the value of $U_{m}$, and, in particular, this change keeps $U_{m}=0$. Thus, increasing $c$ and $l$ by the same small amount changes the period $r$ utility by $U_{c}+U_{l}>0$. This establishes the contradiction. Q.E.D.

This lemma shows that if the solution of the Ramsey problem is interior for the initial price level and the Friedman rule does not hold, then the nominal debt must essentially be zero. If it is not, then no interior solution exists. This lemma implies that when the Friedman rule is violated, the nominal debt must be severely restricted if an interior solution is to exist. For example, if the Friedman rule does not hold in every period, then the nominal liabilities must be zero in every period so that (14) holds. We will use this lemma to show that if the Friedman rule does not hold, then the Ramsey problem is not time consistent.

\section{Time consistency and the Friedman rule in a monetary economy}

Now we give a version of Lucas and Stokey's (1983) definition of time consistency and establish that the Ramsey problem is time consistent if and only if the Friedman rule holds.

We begin with a definition of time consistency. It is convenient to define the Ramsey problem in period $t$, given inherited values for money balances $M_{t-1}$, nominal debt $B_{t-1}$, and real debt $b_{t-1}$, to be the problem of choosing allocations from period $t$ onward, namely, ${ }_{t} c,{ }_{t} l$, and ${ }_{t} m$, and the price level $p_{t}$ (by choosing $M_{t}$ ), to maximize

$$
\max \sum_{s=t}^{\infty} \beta^{s-t} U\left(c_{s}, m_{s}, l_{s}\right)
$$

subject to the resource constraint for $s \geq t$, the implementability constraint in $t$,

$$
\sum_{s=t}^{\infty} \beta^{s-t} R_{s}=-\frac{U_{l t}}{p_{t}}\left(M_{t-1}+\sum_{s=t}^{\infty} Q_{t, s} B_{t-1, s}\right)-\sum_{s=t}^{\infty} \beta^{s-t} U_{l s} b_{t-1, s}
$$

where $Q_{t, s}=\prod_{r=t}^{s-1}\left[1+\left(U_{m r} / U_{l r}\right)\right]$, and the nonnegative interest rate constraint $(7)$.

The Ramsey problem in period $t$ is said to be time consistent for $t+1$ if values exist for nominal money balances $M_{t}$, nominal debt $B_{t}$, and real debt $b_{t}$ that satisfy two conditions. First, 
the nominal money balances $M_{t}$ are consistent with the period $t$ allocation in that $M_{t}=p_{t} m_{t}$. Second, the continuation of the Ramsey allocations in period $t$ from $t+1$ on-namely, ${ }_{t+1} c{ }_{t+1} l$, and ${ }_{t+1} m$ together with the price level $p_{t+1}$ - solve the Ramsey problem in $t+1$, where the price level $p_{t+1}$ is a function of the allocations and the nominal money supply according to

$$
p_{t+1}=\frac{Q_{t, t+1} p_{t}}{q_{t, t+1}}=\beta \frac{U_{l t+1}}{U_{l t}} \frac{M_{t} / m_{t}}{1+\left(U_{m t} / U_{l t}\right)} .
$$

The Ramsey problem in period 0 is time consistent if the Ramsey problem in period $t$ is time consistent for $t+1$ for all $t \geq 0$. In Appendix $\mathrm{C}$, we show that if the Ramsey problem is time consistent in the sense just defined, then the allocations are the outcome of a sustainable Markov equilibrium.

Given this definition, the way to establish that a Ramsey problem in, say, period 0 is time consistent for period 1 is to show how the initial conditions for the period 1 problem, namely, $M_{0}$, $B_{0}$, and $b_{0}$, can be chosen so as to give incentives for the government in period 1 to continue with the allocations chosen by the government in period 0 .

To keep the proofs simple, we assume here that the utility function is weakly increasing in $m$; hence, we can drop the nonnegative interest rate constraint in the Ramsey problem. For later use, however, recall from the proof of Lemma 2 that under this assumption, if $U_{m}=0$, then

$$
U_{m m}=U_{m c}=U_{m l}=0 .
$$

We begin with a simple example that illustrates the main ideas behind Propositions 3 and 4, which give conditions under which the Ramsey problem is time consistent.

Example. Let the utility function $U$ be additively separable in its three arguments. Let $g_{t}$ be zero in all periods, so that $c_{t}=l_{t}$. Let initial government debt have $b_{-1,0}=b>0$ and be zero in all other periods, and let nominal government debt satisfy (14). For the period 0 Ramsey problem, consider the combined first-order conditions for $c_{t}$ and $l_{t}$ for $t \geq 1$,

$$
\left(1+\lambda_{0}\right)\left(U_{c t}+U_{l t}\right)+\lambda_{0} c_{t}\left(U_{c c t}+U_{l l t}\right)=0
$$

and the first-order condition for $m_{t}$ for $t \geq 0$,

$$
\left(1+\lambda_{0}\right) U_{m t}+\lambda_{0} m_{t} U_{m m t}=0
$$


Clearly, $c_{t}$ and $l_{t}$ are constant for $t \geq 1$ and $m_{t}$ is constant for $t \geq 0$. It is easy to show that a constant level of positive taxes are levied in each period $t \geq 1$, so that $U_{c t}+U_{l t}>0$ and is constant for each $t \geq 1$.

To make this allocation time consistent for period 1, we must be able to choose new government debt $B_{0, t}$ and $b_{0, t}$, new nominal money balances $M_{0}$, and a new multiplier $\lambda_{1}$ which support the continuation of the period 0 allocations. To do so, these constructed objects must satisfy the first-order conditions for the Ramsey problem in period 1, namely, the combined first-order conditions for $c_{t}$ and $l_{t}$ for all $t \geq 1$,

$$
\left(1+\lambda_{1}\right)\left(U_{c t}+U_{l t}\right)+\lambda_{1} c_{t}\left(U_{c c t}+U_{l l t}\right)+\lambda_{1} U_{l l t} b_{0 t}=0
$$

and the first-order condition with respect to $m_{t}$ for $t \geq 1$,

$$
\left(1+\lambda_{1}\right) U_{m t}+\lambda_{1} m_{t} U_{m m t}=0
$$

We first show that if the Friedman rule holds, then the allocation can be made time consistent. (By doing so we highlight some of the key ideas in Proposition 3, presented below.) We set $M_{0}+B_{0, t}=0$ and $B_{0, t}=0$ for all $t \geq 1$ and construct $b_{0 t}$ and $\lambda_{1}$ in a way related to that of Lucas and Stokey (1983). Since $c_{t}, l_{t}$, and $m_{t}$ are constant in (29), the level of real government debt $b_{0 t}$ does not vary with $t$; we denote it by $b^{\prime}$. We use (29) to find $b^{\prime}$ as a function of $\lambda_{1}$, namely,

$$
b^{\prime}=-\frac{\left(U_{c t}+U_{l t}\right)}{U_{l l t}}\left(\frac{1}{\lambda_{1}}\right)-\frac{\left(U_{c t}+U_{c c t} c_{t}+U_{l t}+U_{l l t} l_{t}\right)}{U_{l l t}} .
$$

We then substitute $b^{\prime}$ into the period $t=1$ implementability constraint to solve for $\lambda_{1}$. Such a $\lambda_{1}$ can be found if $-\left(U_{c t}+U_{l t}\right) / U_{l l t} \neq 0$, a condition that we will assume in Proposition 3. Finally, we need to verify that the first-order condition for $m_{t}(30)$ holds for the constructed multiplier $\lambda_{1}$. Notice that, if the Friedman rule holds, then by (26), this equation is satisfied for any $\lambda_{1}$. In this sense, when agents are satiated with money, money disappears from the Ramsey problem.

Now we show that if the Friedman rule does not hold, then the period 0 Ramsey problem is not time consistent. (By doing so we highlight some of the key ideas in Proposition 4, presented below.) Lemma 2 implies that if interest rates are always positive, then the nominal government 
debt has to be zero in each period. Motivated by this implication of Lemma 2, we suppose here that the new nominal debt satisfies $M_{0}+B_{0, t}=0$ and $B_{0, t}=0$ for all $t \geq 1$. We argue that with these restrictions on nominal debt, the period 0 allocations cannot be supported. For $t \geq 1$, taxes are levied and the allocations are constant; hence, $b_{0, t}$ is some positive constant $b^{\prime}$ for all $t$. Comparing the first-order conditions for $m_{t}$ in periods 0 and 1 , we conclude that since $U_{m t}>0$ for some $t \geq 1$, then $\lambda_{1}=\lambda_{0}$. Using this multiplier, we evaluate the first-order condition of the period 1 problem (29) at the continuation of the period 0 allocations, which solve (27), to conclude that for all $t \geq 1$,

$$
\left(1+\lambda_{0}\right)\left(U_{c t}+U_{l t}\right)+\lambda_{0} c_{t}\left(U_{c c t}+U_{l l t}\right)+\lambda_{0} U_{l l t} b^{\prime}=\lambda_{0} U_{l l t} b^{\prime}<0
$$

since $U_{l l t}$ is negative and both $\lambda_{0}$ and $b^{\prime}$ are positive and the rest of the terms are zero by $(27)$. This inequality means that at the period 0 allocations, the government has incentive to deviate from the allocations chosen by the period 0 government. Hence, the period 0 Ramsey problem is not time consistent. ${ }^{1}$

At a more abstract level, when the restrictions imposed by Lemma 2 are satisfied, the government in period 0 does not have enough instruments to induce the government in period 1 to follow the continuation of the Ramsey policy. The government in period 0 must find a vector of real bonds and a multiplier for the implementability constraint that satisfy the first-order conditions for consumption and leisure (29), the first-order conditions for real balances (30), and the implementability constraints of the period 1 government at the period 0 Ramsey allocation. When the Friedman rule does not hold, in general, there is no combination of $b^{\prime}$ and $\lambda$ that satisfies all these equations.

We can now use the logic of this example to show that if the Friedman rule holds, then the Ramsey problem is time consistent. To cover the general case, we assume that two regularity conditions hold in each period $t: U_{c t}+U_{l t} \geq 0$, so that taxes are nonnegative, and $U_{c l t}+U_{l l t}<0$, which is essentially normality of consumption. (Lemma 4, introduced and proven in Appendix B, gives sufficient conditions for taxes to be nonnegative.) 
Proposition 3. Assume that the initial nominal government liabilities are all zero, so that (14) holds and our regularity conditions hold. If the Friedman rule holds for each period, then the Ramsey problem in period 0 is time consistent.

The logic of the proof is similar to that of the example and is given in Appendix A. Strictly speaking, in the proof of this proposition, we show that if the maturity structure of the government debt is adequately managed, then the continuation of the Ramsey allocation in period 0 satisfies the first-order conditions of the Ramsey problem faced by the successor governments. An allocation that satisfies the first-order conditions may not solve the Ramsey problem; it could be a local maximum, a minimum, or a saddle point. In Appendix B we give conditions under which the first-order conditions of the Ramsey problem are sufficient for a maximum.

The proof of Proposition 3 makes clear that to ensure time consistency, there is a unique way to restructure the real government debt. Note that there are many ways to restructure the nominal debt. (See Appendix A for details.)

We now consider the converse, namely, that when a solution to the Ramsey problem violates the Friedman rule, the Ramsey problem is not time consistent. We assume the following regularity condition. At a Ramsey allocation, if the Friedman rule does not hold for some period $t$, then

$$
\left(R_{c t}+R_{l t}\right) U_{l m t}-R_{m t}\left(U_{l c t}+U_{l l t}\right) \neq 0
$$

holds, where $R(c, m, l)=c U_{c}+m U_{m}+l U_{l}$. (This regularity condition ensures that the first-order conditions to the Ramsey problem are not collinear.) A simple example for which this regularity condition is satisfied is when the period utility function $U$ is additively separable in leisure. For such preferences, the term on the left side of (31) reduces to $-R_{m t} U_{l l t}$ and the first-order condition (17) implies that $R_{m t}=-U_{m t} / \lambda \neq 0$.

We also assume that in period 0 the government's budget is not balanced, in that

$$
\tau_{0} c_{0}+\left(1-Q_{0,1}\right) m_{0} \neq g_{0}+b_{-1,0}
$$

where $Q_{0,1}=1+\left(U_{m 0} / U_{l 0}\right)$ and $1+\tau_{0}=-U_{c 0} / U_{l 0}$. We then have 
Proposition 4. Suppose that the government's initial nominal liabilities are all zero, so that (14) holds. Assume also that there is some period $r$ in which consumption taxes are levied and in that period the conditions (22) and the regularity condition (31) hold, the normality condition $U_{l c t}+U_{l l t}<0$ holds in all periods, and the government's budget is not balanced in period 0 . If the Ramsey problem is time consistent, then the Friedman rule holds for each period $s \geq 1$.

Proof. We prove this proposition by showing that if the Friedman rule does not hold in some period $s \geq 1$, then the Ramsey problem is not time consistent. By way of contradiction, suppose that the Friedman rule does not hold in $s \geq 1$, but the Ramsey problem is time consistent. We show that this implies that in period 0, the Ramsey allocation first-order conditions for the period 1 problem cannot hold, thus establishing a contradiction.

We first show that all the terms involving the nominal government liabilities in the firstorder conditions for the period 1 problem are zero. Consider taking the first-order conditions with respect to $c_{t}$ and $l_{t}$ in the period 1 Ramsey problem. We claim that in any period $t \geq 1$, terms of the form

$$
Q_{0 t} \frac{\partial Q_{t, t+1}}{\partial c_{t}} \sum_{v=t+1}^{\infty} Q_{t+1, v} B_{-1, v}=0 .
$$

Suppose first that $t$ is some period in which the Friedman rule holds. Then $U_{m t}=0$, and from (26) we know that $\partial Q_{t, t+1} / \partial c_{t}=\left(U_{m c t} U_{l t}-U_{l c t} U_{m t}\right) / U_{l t}^{2}=0$, where we have used $Q_{t, t+1}=1+\left(U_{m t} / U_{l t}\right)$. A similar argument implies that $\partial Q_{t, t+1} / \partial l_{t}=0$; hence, the corresponding terms are also zero under the first-order conditions for $l_{t}$. If $t$ is a period, like period $s$, in which the Friedman rule does not hold, then (21) does hold, and these terms are zero as well. Moreover, for the period 1 problem, the first-order condition with respect to $p_{1}$ implies that terms of the form $\left(M_{0}+\sum_{t=0}^{\infty} Q_{1, t} B_{0, t}\right) / p_{1}=0$.

We now show that the multipliers on the implementability constraints for the Ramsey problems in periods 0 and $1, \lambda_{0}$ and $\lambda_{1}$, satisfy $\lambda_{0}=\lambda_{1}$. To see this, consider the first-order conditions to these problems for period $s$. From (14) we know that $B_{-1, t}$ is zero for all $t \geq 1$. The first 
order-condition for $m_{s}$ has the form of (17), which can be written as

$$
R_{m s} \lambda_{0}+U_{l m s} \lambda_{0} b_{-1, s}=-U_{m s}
$$

Combining the first-order conditions for $c_{s}$ and $l_{s}$ gives

$$
\left(R_{c s}+R_{l s}\right) \lambda_{0}+\left(U_{l c s}+U_{l l s}\right) \lambda_{0} b_{-1, s}=-U_{c s}-U_{l s} .
$$

We can regard (34) and (35) as a system of two linear equations in two unknowns, $\lambda_{0}$ and $\lambda_{0} b_{-1, s}$. For the period 1 Ramsey problem, $U_{m s}>0$ for some $s \geq 1$. Lemma 2 implies that $\sum_{t=s}^{\infty} Q_{1, t} B_{0, t}$ is zero, so that the first-order conditions for the period 1 problem can be written as

$$
\begin{aligned}
& R_{m s} \lambda_{1}+U_{l m s} \lambda_{1} b_{0, s}=-U_{m s} \\
& \left(R_{c s}+R_{l s}\right) \lambda_{1}+\left(U_{l c s}+U_{l l s}\right) \lambda_{1} b_{0, s}=-U_{c s}-U_{l s}
\end{aligned}
$$

which is a system of linear equations in the two unknowns $\lambda_{1}$ and $\lambda_{1} b_{0, s}$. By hypothesis, the Ramsey problem is time consistent; hence, the allocations in the two systems of equations (34)-(35) and (36)-(37) are the same. Our regularity condition (31) implies that there is a unique solution to both and, hence, that $\lambda_{0}=\lambda_{1}$.

Now we will show that there is some period $T$ for which $b_{0, T} \neq b_{-1, T}$. By way of contradiction, suppose not. Since the solution to the Ramsey problem in period 1 is interior, the first-order condition for $p_{1}$ implies that

$$
\frac{\lambda_{1}}{p_{1}}\left(M_{0}+\sum_{t=1}^{\infty} Q_{1, t} B_{0, t}\right)=0 .
$$

Subtracting the product of $\beta$ and the period 1 implementability constraint from the period 0 implementability constraint gives

$$
U_{c} c_{0}+m_{0} U_{m 0}+U_{l 0} l_{0}=-U_{l 0} b_{-1,0},
$$

which implies that the budget must be balanced in period 0 . This is a contradiction. Hence, there must be some period $T$ for which $b_{0, T} \neq b_{-1, T}$. Using $\lambda_{1}=\lambda_{0}$ and $b_{0, T} \neq b_{-1, T}$, evaluate the first-order condition for the period 1 problem in $T$ for the period 0 allocations. That gives

$$
\left(R_{c T}+R_{l T}\right) \lambda_{1}+\left(U_{l c T}+U_{l l T}\right) \lambda_{1} b_{0, T} \neq-U_{c T}-U_{l T}
$$


where we have used the assumption that $U_{l c T}+U_{l l T}<0$. Thus, the continuation of the period 0 allocation cannot solve the period 1 problem. Hence, the Ramsey problem is not time consistent. Q.E.D.

Note that if in the period 0 Ramsey problem, the government's budget is balanced in every period, then the Ramsey problem can be time consistent even if interest rates are strictly positive in all periods. For example, consider an economy in which $g_{t}$ is constant and $b_{-1, t}=B_{-1, t}=0$ for all $t$, so that there is no initial government debt. The period 0 Ramsey allocation is constant and prescribes a balanced budget. The Ramsey problem at any future period is the same as the period 0 Ramsey problem; thus, its solution is the continuation of the period 0 solution. Therefore, the period 0 Ramsey problem is time consistent. Nevertheless, the solution of the period 0 Ramsey problem may have strictly positive interest rates depending on the preferences. For an example of such preferences, see Chari, Christiano, and Kehoe (1996, p. 209).

Clearly, our results, especially Proposition 4, are at odds with the results of Persson, Persson, and Svensson (1987). They construct a nominal debt vector to be inherited by the period 1 government and suppose that with this vector as an initial condition, the period 1 government chooses an interior point for $p_{1}$, so that $0<p_{1}<\infty$. As our Lemma 2 shows, unless the Friedman rule is satisfied, the Ramsey problem in period 1 does not have a solution (with an interior point for $\left.p_{1}\right)$. Thus, the construction by Persson, Persson, and Svensson (1987) is invalidated by endogenous restrictions on the nominal debt vector that they do not take into account.

\section{An analogy with a real economy}

Now we develop the connection between our results for a monetary economy and related results for a real economy. Recall that the monetary economy has two taxes, a tax on consumption goods and a tax on real balances, namely, the nominal interest rate. Here we consider a real economy which has two consumption goods and two consumption taxes - a common tax on both goods and an extra tax on, say, the second consumption good. The extra tax in the real economy corresponds to the nominal interest rate in the monetary economy. It is well known that there is 
a close analogy between the optimality of uniform commodity taxation in the real economy, when the second consumption tax is zero, and the optimality of the Friedman rule in the monetary economy, when the nominal interest rate is zero. (See Chari, Christiano, and Kehoe 1996.) We show that this close analogy extends to the time consistency of the Ramsey policies.

In our monetary economy, we have shown that the incentive to inflate away nominal government debt severely restricts the government in any period from using nominal debt to influence the behavior of its successors. In effect, the government is endogenously forced to use only one type of debt, real debt, to influence its successors. Here we imitate these endogenous restrictions on debt by exogenously imposing that the government has access to only one real bond of all maturities. We show that with this restriction, the Ramsey policies are time consistent if and only if it is optimal for taxes to be uniform in the sense that in each period it is optimal to tax the two consumption goods at the same rate.

The resource constraint for this economy is

$$
c_{1 t}+c_{2 t}+g_{t}=l_{t}
$$

where $c_{1 t}$ and $c_{2 t}$ are the consumption goods, $g_{t}$ is government consumption, and $l_{t}$ is labor. The utility function is

$$
\sum_{t=0}^{\infty} \beta^{t} U\left(c_{1 t}, c_{2 t}, l_{t}\right)
$$

and the period 0 budget constraint is

$$
\sum_{t=0}^{\infty} q_{0 t}\left\{\left(1+\tau_{t}\right)\left[c_{1 t}+\left(1+\tau_{2 t}\right) c_{2 t}\right]-l_{t}\right\}=\sum_{t=0}^{\infty} q_{0 t} b_{-1 t}
$$

where $q_{0 t}$ is the price of one unit of consumption, $\tau_{t}$ is the common tax on both consumption goods, $\tau_{2 t}$ is an extra tax on the second consumption good, and $b_{-1}$ is the vector of initial real government debt of all maturities. The first-order conditions for $c_{1 t}$ and $c_{2 t}$ imply that $U_{2 t} / U_{1 t}=1+\tau_{2 t}$ and, hence, that consumption taxes are uniform; that is, $\tau_{2 t}=0$ for all $t$ if and only if $U_{1 t}=U_{2 t}$ for all t. The implementability constraint for this economy is

$$
\sum_{t=0}^{\infty} \beta^{t} R\left(c_{1 t}, c_{2 t}, l_{t}\right)=-\sum_{t=0}^{\infty} \beta^{t} U_{l t} b_{-1 t},
$$


where $R\left(c_{1}, c_{2}, l\right)=c_{1} U_{1}+c_{2} U_{2}+l U_{l}$.

In this real economy, the Ramsey problem in period 0 is to maximize (42) subject to (41) and (44) given an initial real debt of $b_{-1}$. The following well-known result is the analog of Proposition 1: If the utility function is separable and homothetic, so that $U\left(c_{1}, c_{2}, l\right)=u\left(w\left(c_{1}, c_{2}\right), l\right)$ for some homogeneous function $w$, then uniform commodity taxation is optimal.

We now establish a proposition for this economy that is the analog of Propositions 3 and 4 . Time consistency is defined in the obvious way. We assume the following regularity conditions. As in Proposition 3, here we assume that at the Ramsey allocations $U_{c t}+U_{l t} \geq 0$, so that taxes are nonnegative, and $U_{l c t}+U_{l l t}<0$, which is essentially normality of consumption. Analogously to Proposition 4, we assume that in any Ramsey allocation, if in period $t, U_{1 t} \neq U_{2 t}$, then

$$
\left(R_{1 t}+R_{l t}\right)\left(U_{2 l t}+U_{l l t}-R_{2 t}+R_{l t}\right)\left(U_{1 l t}+U_{l l t}\right) \neq 0 .
$$

This regularity condition ensures that the first-order conditions for the two consumption goods are not collinear when the taxes are different. It can be shown that the regularity condition (45) holds when the utility function is additively separable in leisure.

Proposition 5. Assume that the regularity condition holds and the government's budget is not balanced under the Ramsey policies in period 0. If the utility function is weakly separable in leisure and uniform commodity taxation is optimal, then the Ramsey problem is time consistent. Conversely, if the Ramsey problem is time consistent, then uniform commodity taxation is optimal.

The proof for the claim that if consumption taxes are uniform, then the Ramsey problem is time consistent uses a construction for the real debt $b_{0}$ and the multiplier $\lambda_{0}$ identical to the proof for Proposition 3 (in Appendix A). The proof for the claim that time consistency implies that consumption taxes are uniform is a simpler version of the proof for Proposition 4 because here we do not have to deal with nominal debt.

To gain some intuition for Proposition 5, consider the first-order conditions for the period 1 Ramsey problem for a $T$-period version of this real economy. Adding the first-order conditions 
for $c_{1 t}$ and $l_{t}$, we obtain

$$
R_{1 t}+R_{l t}+\left(U_{1 l t}+U_{l l t}\right) b_{0 t}=-\frac{\left(U_{1 t}+U_{l t}\right)}{\lambda_{1}}
$$

while subtracting the first-order conditions for $c_{1 t}$ and $c_{2 t}$, we obtain

$$
R_{1 t}-R_{2 t}+\left(U_{1 l t}-U_{2 l t}\right) b_{0 t}=-\frac{\left(U_{1 t}-U_{2 t}\right)}{\lambda_{1}}
$$

The implementability constraint is

$$
\sum_{t=1}^{T} \beta^{t} R\left(c_{1 t}, c_{2 t}, l_{t}\right)=-\sum_{t=1}^{T} \beta^{t} U_{l t} b_{0 t} .
$$

For a given allocation, these equations form a linear system of $2 T+1$ equations in $T+1$ unknowns, which are the $b_{0 t}$ from $t=1, \ldots, T$ and $1 / \lambda_{1}$.

To make the period 0 Ramsey problem time consistent, we must be able to choose the $T+1$ unknowns to solve the $2 T+1$ equations. In general, this cannot be done; hence, the Ramsey problem is not time consistent. When uniform commodity taxation is optimal, $U_{1 t}=U_{2 t}$, and with weak separability, $U_{1 l t}=U_{2 l t}$. Hence, neither $b_{0 t}$ nor $\lambda_{1}$ enters into (47). Thus, the linear system reduces to $T+1$ equations in $T+1$ unknowns, and the Ramsey problem is time consistent. Conversely, if the Ramsey problem is time consistent, it must be that $T$ of these equations are redundant. Given our regularity conditions, we conclude that $U_{1 t}=U_{2 t}$, or that uniform commodity taxation is optimal.

Consider the analogous equations for a $T$-period monetary model in which the utility function is weakly increasing in $m$. (To make this analogy complete, we include a tax on real balances in period $T$ to imitate the effects of nominal interest rates in a finite-horizon monetary economy.) Here we impose that the nominal government debt is zero, except in period 0 , for which we set $B_{0,0}=-M_{0}$. This is without loss of generality given our previous analysis: in each period, either $U_{m t}>0$ and Lemma 3 applies or $U_{m t}=0$ and (26) holds. Either way, the terms in the first-order conditions involving nominal debt drop out. For this economy, the first-order conditions for $c_{t}$ and $l_{t}$ combined give

$$
R_{c t}+R_{l t}+\left(U_{l c t}+U_{l l t}\right) b_{0, t}=-\frac{\left(U_{c t}+U_{l t}\right)}{\lambda_{1}}
$$


while the first-order condition for money is

$$
R_{m t}+U_{l m t} b_{0 t}=\frac{U_{m t}}{\lambda_{1}}
$$

The implementability constraint is

$$
\sum_{t=1}^{T} \beta^{t} R\left(c_{t}, m_{t}, l_{t}\right)=-\sum_{t=1}^{T} \beta^{t} U_{l t} b_{0 t} .
$$

Here, as in the real economy, these equations form a linear system in $2 T+1$ equations and $T+1$ unknowns. In general, this system has too many equations for the unknowns, and the Ramsey problem is not time consistent. When the Friedman rule is optimal, $U_{m t}=0$, and using either weak separability or (26), we know that $U_{l m t}=0$ and neither $b_{0 t}$ nor $\lambda_{1}$ enters (49). Thus, the linear system reduces to $T+1$ equations in $T+1$ unknowns, and the Ramsey problem is time consistent. Conversely, if the Ramsey problem is time consistent, it must be that $T$ equations are redundant. Given our regularity conditions, we conclude that the $T$ redundant equations are the first-order conditions for money, which implies that $U_{m t}=0$. Thus, the Friedman rule is optimal.

\section{Conclusions and Extensions}

We have considered a simple economy similar to that in Lucas and Stokey (1983). We have found that monetary and fiscal policies are time consistent if and only if the Friedman rule is optimal. The key ideas behind the results are the following. First, there is little freedom in using nominal debt to influence successor governments; rather, all of the influence comes from the appropriate setting of real debt. Second, when the Friedman rule is not optimal, then each government does not have enough free debt instruments to adequately control the incentives of its successor to carry out its plan. When the Friedman rule is optimal, the government has no desire to use one of its taxes, the nominal interest rate, and the free debt instrument, real debt, is rich enough to control the incentives of its successor in setting the remaining tax, the consumption tax. Finally, we have shown the Friedman rule is optimal for preferences that are widely used in applied work. Hence, our results suggest that, in practice, the type of time consistency problem considered here can be adequately solved by a careful management of the government debt. 
We have focused our attention on a particular setup. Here we discuss how our results extend to a variety of related setups. Briefly, we argue that, essentially, our results remain valid in these related setups.

First, we have assumed that the government levies consumption taxes, while most of the literature assumes the government levies labor income taxes. We did so because we wanted the Friedman rule to be optimal for a wide set of preferences. With labor income taxes and real debt of arbitrary maturities, the Friedman rule is optimal for a much smaller set while the rest of the propositions hold with essentially no changes.

Second, we have focused on a money-in-the-utility-function framework. In an appendix, available upon request, we discuss appropriately modified versions of these results for cash-credit economies. A cash-credit economy can be mapped into our framework, but the resulting moneyin-the-utility-function model does not naturally have $U$ weakly increasing in real balances. Hence, we need to deal carefully with the potentially binding nonnegative interest rate constraint $U_{m t} \geq 0$. The analog of Proposition 3 holds for such an economy. A slightly weaker version of Proposition 4 holds: If nominal interest rates are positive in all periods, then the Ramsey plan can not be time consistent.

Third, we have followed the literature and have assumed that end-of-period real money balances enter in the utility function. An alternative sometimes considered is that the beginningof-period real money balances enter the utility function. It is easy to show that the analog of Proposition 3 holds: If the Friedman rule is optimal then the Ramsey plan is time consistent. It is an open question as to what version of Proposition 4 holds. It is clear that our current proof does not apply because it is based on Lemma 2 which does not hold here. With this timing any change in the initial price level necessarily affects the initial real balances. Thus, increasing the price level to inflate away the nominal debt has real costs. We leave the exact characterization of the analog of Proposition 4 for future research. (We discuss all three of the extensions discussed here in an appendix that is available upon request.) 


\section{Appendix A: Proofs of Propositions 1, 2, and 3 and Discussion of Alternative Ways to Restructure Nominal Debt}

Proof of Proposition 1. Assume, by way of contradiction, that $U_{m t}>0$. We can arrange the first-order conditions for consumption $c_{t}$ and real money balances $m_{t}$ to be

$$
\begin{aligned}
& (1+\lambda)+\lambda\left(\frac{U_{c c t} c_{t}+U_{c m t} m_{t}}{U_{c t}}\right)+\lambda\left(l_{t}+b_{-1 t}\right) \frac{U_{l c t}}{U_{c t}}=\frac{\gamma_{t}}{U_{c t}} \\
& (1+\lambda)+\lambda\left(\frac{U_{c m t} c_{t}+U_{m m t} m_{t}}{U_{m t}}\right)+\lambda\left(l_{t}+b_{-1 t}\right) \frac{U_{l m t}}{U_{m t}}=0 .
\end{aligned}
$$

Differentiating (19) with respect to $\alpha$ and evaluating it at $\alpha=1$ gives that

$$
\frac{c_{t} U_{c m t}+m_{t} U_{m m t}}{U_{m t}}=\frac{c_{t} U_{c c t}+m_{t} U_{c m t}}{U_{c t}} .
$$

By weak separability, $U_{l c t} / U_{c t}=U_{l m t} / U_{m t}$. Subtracting (50) from (51) using (52) and weak separability gives that $\gamma_{t} / U_{c t}=0$, which is a contradiction since $\gamma_{t}$ and $U_{c t}$ are strictly positive. Q.E.D.

Proof of Proposition 2. First we prove that the Friedman rule solves the Ramsey problem under the conditions of Proposition 2 by showing that under our hypotheses we can construct a solution to the first-order conditions and the implementability constraint that satisfies the Friedman rule.

As a preliminary result, we show that the satiation level of money $m^{*}(c, l)=c g(l)$ for some positive and increasing function $g(l)$ and that at that satiation level

$$
U_{m c}+U_{m m} g(l)=0 \text { and } U_{m m} c g^{\prime}(l)+U_{m l}=0 .
$$

To see this, note that if $U_{m}(\alpha c, \alpha m, l)=0$ for all $\alpha$, we can set $\alpha=1 / c$ and define $m^{*}$ implicitly as $U_{m}\left(1, m^{*}(c, l) / c, l\right)=0$. Clearly, $m^{*}$ is of the form $c g(l)$. Differentiating $U_{m}(c, c g(l), l)=0$ with respect to $c$ and with respect to $m$ gives (53). To see that $g$ is increasing, notice that if $U_{m m}<0$, then $U_{m l} \geq 0$ if and only if $g^{\prime}(l) \geq 0$. If $U_{m m}=0$ at the point where $U_{m}=0$, then, as in (26), $U_{m c}=U_{m l}=0$.

We establish our result by constructing an allocation that solves the first-order conditions of the Ramsey problem in the monetary economy using the first-order conditions for a corresponding real economy. To do so, define $\bar{U}(c, l)=U\left(c, m^{*}(c, l), l\right)$, and define the Ramsey problem for the corresponding real economy as choosing $\left\{c_{t}, l_{t}\right\}$ to maximize $\sum \beta^{t} \bar{U}\left(c_{t}, l_{t}\right)$ subject to $c_{t}+g_{t}=l_{t}$ and the implementability constraint

$$
\sum_{t=0}^{\infty} \beta^{t}\left[\bar{U}_{c t} c_{t}+\bar{U}_{l t}\left(l_{t}+b_{-1, t}\right)\right]=0 .
$$


Denote the solution as $\left\{c_{t}^{*}, l_{t}^{*}\right\}$ and the multipliers for the resource constraints and the implementability constraints as $\left\{\gamma_{t}^{*}\right\}$ and $\lambda^{*}$.

For the corresponding monetary economy, we need to define the multiplier on the constraint $U_{m t} \geq 0$. Let this multiplier be given by

$$
\eta_{t}^{*}=\lambda^{*} m_{l}\left(c_{t}^{*}, l^{*}\right)\left(l_{t}^{*}+b_{-1 t}\right) .
$$

Notice that $\eta_{t}^{*} \geq 0$ since $l_{t}^{*}+b_{-1 t} \geq 0$ and $m_{l}\left(c_{t}^{*}, l^{*}\right)=c_{t}^{*} g^{\prime}\left(l_{t}^{*}\right) \geq 0$. Let $m_{t}^{*}=m^{*}\left(c_{t}^{*}, l_{t}^{*}\right)$. We claim that $\left\{c_{t}^{*}, m_{t}^{*}, l_{t}^{*}\right\}$ and the multipliers $\lambda^{*}$ and $\left\{\gamma_{t}^{*}, \eta_{t}^{*}\right\}$ solve the first-order conditions and the implementability constraint of the Ramsey problem in the monetary economy. Clearly, the allocation is resource feasible. It remains to be shown that the first-order conditions with respect to $m_{t}, c_{t}$, and $l_{t}$ as well as the implementability constraint are satisfied.

We now show that the first-order condition for money

$$
\left(1+\lambda^{*}\right) U_{m t}+\lambda^{*}\left[U_{m c t} c_{t}^{*}+U_{m m t} m_{t}^{*}+U_{m l t}\left(l_{t}^{*}+b_{-1, t}\right)\right]+\eta_{t}^{*} U_{m m t}=0
$$

holds at the constructed allocations and multipliers. At our constructed allocation, $U_{m t}=$ 0 . Multiplying the first equality in (53) by $\lambda^{*} c_{t}^{*}$ and using the definition of $m^{*}$, we obtain $\lambda^{*}\left(U_{m c t} c_{t}^{*}+U_{m m t} m_{t}^{*}\right)=0$. Using (53) to solve for $U_{m l t}$ and the definition of $\eta_{t}^{*}$, we get

$$
\lambda\left(l_{t}^{*}+b_{-1 t}\right) U_{m l t}+\eta_{t}^{*} U_{m m t}=U_{m m t}\left[-\lambda^{*}\left(l_{t}^{*}+b_{-1 t}\right) c_{t}^{*} g^{\prime}\left(l_{t}^{*}\right)+\eta_{t}^{*}\right] .
$$

Hence, the first-order condition for $m_{t}$ holds.

The first-order condition with respect to $c_{t}$ in the real economy is

$$
\left(1+\lambda^{*}\right) \bar{U}_{c t}+\lambda^{*}\left[\bar{U}_{c c t} c_{t}^{*}+\bar{U}_{c l t}\left(l_{t}^{*}+b_{-1, t}\right)\right]=\gamma_{t}^{*}
$$

Using the definition of $\bar{U}$ and the form of $m^{*}$ and evaluating the derivatives at the candidate allocation, we have that $\bar{U}_{c}=U_{c}, \bar{U}_{c c}=U_{c c}+U_{c m} m_{c}$, and $\bar{U}_{c l}=U_{c l}+U_{m l} m_{c}$. From (53), we obtain $U_{m l} m_{c}=U_{m c} m_{l}$. Using all of these expressions and the definition of $\eta_{t}^{*}$, we obtain

$$
U_{c t}\left(1+\lambda^{*}\right)+\lambda^{*}\left(U_{c c t} c_{t}^{*}+U_{c m} m_{t}^{*}\right)+\lambda^{*} U_{c l t}\left(l_{t}^{*}+b_{-1 t}\right)+\lambda^{*} \eta_{t}^{*}=\gamma_{t}^{*}
$$

which is the first-order condition for $c_{t}$ in the monetary economy. An analogous argument holds for the first-order conditions with respect to $l_{t}$. Finally, from $m_{t}^{*}=m\left(c_{t}^{*}, l_{t}^{*}\right), \bar{U}_{c t}=U_{c t}, \bar{U}_{l t}=U_{l t}$, and $U_{m t}=0$, it is immediate that the implementability constraint in the real economy implies the implementability constraint in the monetary economy. Q.E.D.

Proof of Proposition 3. Now we prove that if the Friedman rule holds under the conditions of Proposition 3, then the Ramsey problem is time consistent.

We begin this proof by showing that the Ramsey problem for period 0 is time consistent for period 1 by constructing the appropriate initial conditions for the period 1 Ramsey problem, 
namely, $M_{0}, B_{0}$, and $b_{0}$ together with a period 1 multiplier $\lambda_{1}$, so that the first-order conditions and the implementability constraint for the period 1 Ramsey problem hold when evaluated at the continuation of the period 0 Ramsey allocations. For the nominal assets, we set $M_{0}+B_{0,0}=0$ and $B_{0, t}=0$ for $t \geq 1$. (The breakdown of $M_{0}$ and $B_{0,0}$ is irrelevant as long as $M_{0}>0$.)

We construct the values for $b_{0}$ and $\lambda_{1}$ in a way similar to that of Lucas and Stokey (1983). Consider the combined first-order conditions for $c_{t}$ and $l_{t}$ from (15) and (16), which can be rewritten as

$$
b_{0, t}=-\left(\frac{1}{\lambda_{1}}\right) \frac{\left(U_{c t}+U_{l t}\right)}{\left(U_{l c t}+U_{l l t}\right)}-\frac{\left(R_{c t}+R_{l t}\right)}{\left(U_{l c t}+U_{l l t}\right)},
$$

which gives our expression for $b_{0, t}$ for an arbitrary $\lambda_{1}$. To construct $\lambda_{1}$, we substitute this expression for $b_{0, t}$ into the period 1 implementability constraint. Given our assumptions, the fraction $\left(U_{c t}+\right.$ $\left.U_{l t}\right) /\left(U_{l c t}+U_{l l t}\right)$ is negative, and there is a unique solution for $\lambda_{1}$.

It remains to be shown that the first-order conditions for $m_{t}$ in the period 1 problem

$$
U_{m t}+\lambda_{1} R_{m t}=-\lambda_{1} U_{l m t} b_{0, t}
$$

hold. Since $U_{m t}=0$, it follows from (26) that $R_{m t}=U_{m t}+c_{t} U_{c m t}+m_{t} U_{m m t}+l_{t} U_{m l t}=0$. Since both sides of (58) are identically zero regardless of the multiplier, these first-order conditions trivially hold. Q.E.D.

\section{Alternative Ways to Restructure Nominal Debt}

Here we discuss alternative ways to restructure nominal debt that still lead to time consistency. Essentially, these ways require that nominal debt vectors satisfy

$$
M_{0}+\sum_{t=0}^{\infty} B_{0, t}=0
$$

so that when the Friedman rule holds, the value of the initial nominal liabilities of the government of period 1 is zero and the value of nominal liabilities for any period $s \geq 1$ is negative, in that

(60) $\quad \sum_{t=s}^{\infty} B_{0, t} \leq 0$

We refer to condition (60) as requiring negative tails of the nominal liabilities inherited in period 1. In the following lemma, we assume that the multiplier on the implementability constraint is positive. Lemma 5 in Appendix B gives sufficient conditions for this to occur. We have

Lemma 3. If the Friedman rule is optimal in an economy in which the government's initial nominal liabilities all are zero, so that (14) holds and the multiplier on the implementability constraint is positive, then the Friedman rule is also optimal in an economy in which this debt has a present value of zero and has negative tails, so that (59) and (60) hold. 
Briefly, if the Friedman rule holds, then, since interest rates must be nonnegative, any deviation from the Friedman rule has to lower some $Q_{t, t+1}$. Under the negative tails condition, such a deviation puts smaller weight on the negative tail and, hence, raises the present value of initial nominal debt. This deviation does not improve utility, and the Friedman rule is optimal.

Proof. Consider a relaxed Ramsey problem in which the implementability constraint is written as an inequality and instead of connecting the bond prices to the allocations through $Q_{1, t}=\prod_{s=1}^{t-1}\left[1+\left(U_{m s} / U_{l s}\right)\right]$, we simply add the variables $Q_{t, t+1}$ for all $t$ as new extra choice variables that must only satisfy $0 \leq Q_{t, t+1} \leq 1$ and $Q_{0, t}=Q_{0,1} \ldots Q_{t-1, t}$. Since the multiplier on the implementability constraint is positive, setting $Q_{t, t+1}$ to minimize the present value of nominal liabilities is clearly optimal. Under the negative tails assumption and (59), the lower bound for this present value is zero and is attained at $Q_{t, t+1}=1$. Substituting in this value for $Q_{t, t+1}$, we see that the remaining problem is the same as one for the economy with zero nominal liabilities in each period, in which the Friedman rule is optimal. Thus, the solution to the relaxed problem is feasible for the original unrelaxed problem and, hence, is the solution. Q.E.D.

\section{Appendix B: Sufficient Conditions for the First-Order Approach to Be Valid}

It is customary in this literature to look only at first-order conditions of the Ramsey problem without checking the second-order conditions. This custom led Calvo and Obstfeld (1990) and Persson, Persson, and Svensson (1989) to conjecture that the mistake in Persson, Persson, and Svensson (1987) was due to a failure of the second-order conditions. For completeness we describe preferences for which the first-order conditions of the Ramsey problem are sufficient for an optimum. It should be clear that even if we made such assumptions, a lack of attention to subtle corners would still lead to a mistake.

Assume that the utility function $U$ is weakly separable and homothetic, so that $U(c, m, l)=$ $u(w(c, m), l)$ for a function $w$ homogeneous of degree one. Let the satiation level of real balances be $m^{*}(c, l)=k c$, and normalize $w(1, k)=1$, so that, abusing notation, we can write $u(c, l)=u(c w(1, k), l)$. Consider preferences that for each $g_{t}, b_{-1 t}$ satisfy the following secondorder condition:

$$
c\left(u_{c c c}+u_{c c l}\right)+2\left(u_{c c}+u_{c l}\right)+\left(l+b_{-1 t}\right)\left(u_{l l l}+u_{l l c}\right)+2\left(u_{l l}+u_{l c}\right) \leq 0
$$

for all $c, l$ such that $c+g_{t}=l$.

An example of preferences that satisfy (61) is when $u(c, l)=\left(c^{1-\sigma}-1\right) /(1-\sigma)-A l^{1+\theta}$ for $0 \leq \sigma \leq 1, A>0$, and $\theta \geq 1$, provided that $g_{t}+b_{-1 t} \geq 0$. Another example is when $u(c, l)$ is quadratic in its arguments and $c$ and $l$ are normal goods. (See Lucas and Stokey 1983.) We then have 
Proposition 6. Assume that $U$ is weakly separable and homothetic and that (14) holds. Consider a Ramsey problem in which the implementability constraint is written as the inequality

$$
\sum_{t=0}^{\infty} \beta^{t}\left[U_{c t} c_{t}+U_{m t} m_{t}+U_{l t}\left(l_{t}+b_{-1 t}\right)\right] \geq 0 .
$$

If the second-order condition (61) holds, then the solution of this problem is unique.

Proof. Since preferences are homothetic and separable, Proposition 1 ensures that if an allocation solves the first-order conditions of the Ramsey problem, then $U_{m}(c, m, l)=0$. Based on this result, consider the problem of maximizing $\sum_{t=0}^{\infty} \beta^{t} u\left(c_{t}, l_{t}\right)$ subject to the resource constraint and the implementability constraint written as the inequality

$$
\sum_{t=0}^{\infty} \beta^{t}\left[u_{c}\left(c_{t}, l_{t}\right) c_{t}+u_{l}\left(c_{t}, l_{t}\right)\left(l_{t}+b_{-1 t}\right)\right] \geq 0 .
$$

Using the resource constraint to solve for consumption, we can write the implementability constraint as $\sum \beta^{t} f\left(l_{t}, b_{-1 t}, g_{t}\right) \geq 0$, where $f(l ; b, g) \equiv u_{c}(l-g, l)(l-g)+u_{l}(l-g, l)(l+b)$.

Under the conditions in $(61)$, the function $f\left(l_{t}, b_{-1 t}, g_{t}\right)$ is concave with respect to $l_{t}$; hence, the feasible set is convex. Q.E.D.

This proposition ensures that, if we can write the implementability constraint as an inequality, then there is a unique solution of the first-order conditions which is a global maximum. Clearly, we can write the implementability constraint as an inequality whenever the multiplier on this constraint is positive.

We now establish two results which ensure that this multiplier is positive. In Lemma 4, we give sufficient conditions for the period 0 Ramsey problem to have positive taxes in all periods. In Lemma 5, we show that in the period $s$ Ramsey problem, if taxes are positive in all periods, then the multiplier on the implementability constraint is positive. If we combine these lemmas with Proposition 5, we can conclude that it is sufficient to use first-order conditions for any period $s$ Ramsey problem.

Lemma 4. Assume that $U$ is weakly separable and homothetic, $g_{t}+b_{-1, t}>0$ for all $t$, and nominal liabilities are zero in every period, so that (14) holds. If at the Ramsey allocations $u_{c c t}+u_{c l t}<0$ and $u_{l l t}+u_{c l t}<0$ for all $t$, then consumption taxes are charged every period, so that $U_{c t}+U_{l t} \geq 0$ for all $t$.

Proof. Here we consider a Ramsey problem for a real economy with $u(c, l)=$ $U\left(c, m^{*}(c, l), l\right)$. Adding the first-order condition for $c_{t}$ and $l_{t}$ gives

$$
\left(1+\lambda_{0}\right)\left(u_{c t}+u_{l t}\right)+\lambda_{0}\left[\left(u_{c c t}+u_{c l t}\right) c_{t}+\left(u_{l l t}+u_{l c t}\right)\left(l_{t}+b_{-1 t}\right)\right]=0 .
$$

Clearly, $l_{t}+b_{-1 t}>0$ since $g_{t} \leq l_{t}$ from feasibility and $g_{t}+b_{-1, t}>0$ by assumption. Hence, using the assumptions that $u_{c c}+u_{c l}<0$ and $u_{l l}+u_{l c}<0$, we obtain

$$
\left(u_{c c t}+u_{c l t}\right) c_{t}+\left(u_{l l t}+u_{l c t}\right)\left(l_{t}+b_{-1 t}\right)<0 .
$$


The assumption that $g_{t}+b_{-1 t}>0$ for all $t$ implies that $\lambda_{0}>0$ (as in Lucas and Stokey 1983, p. 70); this is easy to show. Hence, $u_{c t}+u_{l t}>0$. Finally, when $m_{t}=m^{*}\left(c_{t}, l_{t}\right)$, we have that $U_{c t}+U_{l t}=u_{c t}+u_{l t}$. Q.E.D.

Lemma 5. Assume that $U$ is weakly separable and homothetic and nominal liabilities are zero in every period, so that (14) holds. Consider an allocation that solves the first-order conditions of a Ramsey problem in period $s$. If for all $t, u_{c c t}+u_{c l t}<0, u_{l l t}+u_{c l t}<0$, and $U_{c t}+U_{l t} \geq 0$ for all $t$, then the multiplier of the implementability constraint, $\lambda_{s}$, is positive.

Proof. By Proposition 1, without loss of generality, we consider the Ramsey problem where $m_{t}=m^{*}\left(c_{t}, l_{t}\right)$ and denote $u(c, l)=U\left(c, m^{*}(c, l), l\right)$. We first show that $l_{r}+b_{-1 r}>0$, for some period $r$. If this were not the case, then $l_{t}+b_{-1 t} \leq 0$ for all $t$. But then the implementability constraint

$$
\sum_{t=s}^{\infty} \beta^{t}\left[u_{c t} c_{t}+u_{l t}\left(l_{t}+b_{-1 t}\right)\right]=0
$$

cannot hold since $u_{c t}>0>u_{l t}$. Now we consider the period $r$ for which $l_{r}+b_{-1 r}>0$. Adding the first-order condition with respect to $c_{r}$ and $l_{r}$, we obtain

$$
0=\left(1+\lambda_{s}\right)\left(u_{c r}+u_{l r}\right)+\lambda_{s}\left[\left(u_{c c r}+u_{c l r}\right) c_{r}+\left(u_{l l r}+u_{l c r}\right)\left(l_{r}+b_{-1 r}\right)\right]
$$

From $u_{c r}+u_{l r}=U_{c r}+U_{l r} \geq 0$ and our other assumptions, it follows that $\lambda_{s}>0$. Q.E.D.

\section{Appendix C: Relating Time Consistency to Sustainable Plans and Credible Policies}

Here we relate Lucas and Stokey's (1983) notion of time consistency to the literature on sustainable plans and credible policies. We show that if the solution to the Ramsey problem is time consistent, then it is sustainable. More precisely, we show that the Ramsey allocations and policies are sustainable outcomes generated by a Markov sustainable equilibrium. Note that the converse is clearly not true; sustainable outcomes are not typically time consistent.

In the Lucas-Stokey definition of time consistency, the government in period 0 solves a problem under the presumption that it has the ability to commit to all its future policies, and consumers act under this presumption as well. What the government in period 0 actually gets to set, however, are the period 0 policies, including the new initial conditions for the government to face in period 1 . The problem in period 0 is time consistent for the problem in period 1 if initial conditions exist such that the government in period 1, under a similar presumption about commitment, chooses to continue with the allocations and policies chosen by the government in period 0 . Under this definition, the government in period 0 does not explicitly think through 
how altering the initial conditions for the government of period 1 affects the future government's choices, since the government in period 0 simply presumes it can commit to all future policies.

The sustainable plan literature takes a lack of commitment as given and explicitly builds it into the definition of an equilibrium. In this definition, the government in period 0 realizes both that it cannot commit to all its future policies and that consumers realize that. This government also explicitly thinks through how altering the initial conditions for the period 1 problem affects the choices of the period 1 government.

In the sustainable plan literature, the lack of commitment is modeled by having the government choose policy sequentially. Consumer allocations, prices, and government policy are specified as functions of the history of past policies of the government. These functions specify behavior for any possible history, even for histories in which the government deviates from prescribed behavior.

In contrast, the time consistent equilibrium simply specifies a sequence of allocations, prices, and policies and is thus not directly comparable to a sustainable equilibrium. Along the equilibrium path, however, a sustainable equilibrium generates a particular sequence of allocations, prices, and policies, called a sustainable outcome, which is comparable to the sequences specified by a time consistent equilibrium.

For a version of the Lucas and Stokey (1983) economy without money, Chari and Kehoe (1993) show that the sustainable outcome generated by a Markov sustainable equilibrium solves a simple programming problem. With a little work, their results can be extended to our economy, and it can be shown that for some given initial conditions $M_{-1}, b_{-1}$, and $B_{-1}$, the allocations $\left({ }_{0} c,{ }_{0} m,{ }_{0} l\right)$ are sustainable Markov allocations if and only if they are part of the solution to the following programming problem: Choose allocations $\left({ }_{0} c,_{0} m,{ }_{0} l\right)$, a nominal money supply $M_{1}$, and real and nominal government debt $b_{1}$ and $B_{1}$ to solve the sustainable Markov problem

$$
V_{0}\left(M_{-1}, b_{-1}, B_{-1}\right)=\max \sum_{t=0}^{\infty} \beta^{t} U\left(c_{t}, m_{t}, l_{t}\right)
$$

subject to the resource constraint for $t \geq 0$, the implementability constraint for all $t=0$

$$
\sum_{t=0}^{\infty} \beta^{t} R_{t}=-\frac{U_{l 0}}{p_{0}}\left(M_{-1}+\sum_{t=0}^{\infty} Q_{0, t} B_{-1, t}\right)-\sum_{t=0}^{\infty} \beta^{t} U_{l t} b_{-1, t}
$$

and for $t=1$

$$
\sum_{t=1}^{\infty} \beta^{t-1} R_{t}=-\frac{U_{l 1}}{p_{1}}\left(M_{0}+\sum_{t=1}^{\infty} Q_{1, t} B_{0, t}\right)-\sum_{t=1}^{\infty} \beta^{t-1} U_{l t} b_{0, t}
$$

and the sustainability constraint for all $t>0$

$$
\sum_{s=t}^{\infty} \beta^{s-t} U\left(c_{t}, m_{t}, l_{t}\right) \geq V_{t}\left(M_{0}, b_{0}, B_{0}\right)
$$

where $Q_{0, t}=\prod_{s=0}^{t-1}\left[1+\left(U_{m s} / U_{l s}\right)\right]$ and $p_{1}=M_{1} / m_{1}$ and the functions $V_{t}\left(M_{t-1}, b_{t-1}, B_{t-1}\right)$ are defined recursively by (62). The sustainability constraint captures the restriction that whatever 
sequence of allocations from period 0 to infinity is contemplated by the government in period 0 , given the state variables $\left(M_{0}, b_{1}, B_{1}\right)$ that this government passes to the government in period 1 , the government in period 1 has an incentive to implement the continuation of these allocations from period 1 onward. The government in period 1 faces a similar constraint with respect to the government in period 2 and so on, for the government in all future periods.

Notice that the sustainable Markov problem is essentially the Ramsey problem in period 0 with two extra constraints: the implementability constraint in period 1 and the sustainability constraint with extra choice variables $\left(M_{0}, b_{1}, B_{1}\right)$ and $p_{1}$. From the definition of time consistency and the sustainable Markov problem, we have the next proposition.

Proposition 7. If the Ramsey problem is time consistent in the sense of Section 2, then the Ramsey allocations are Markov sustainable allocations.

Proof. Our previous propositions contain the essence of the proof. Let $V_{0}^{R}\left(M_{-1}, b_{-1}\right.$, $\left.B_{-1}\right)$ denote the value of the Ramsey problem in period 0 with state variables $\left(M_{-1}, b_{-1}, B_{-1}\right)$. Since the Ramsey problem is a less constrained version of the sustainable Markov problem, its value is necessarily higher, so that

$$
V_{0}^{R}\left(M_{-1}, b_{-1}, B_{-1}\right) \geq V_{0}\left(M_{-1}, b_{-1}, B_{-1}\right)
$$

Thus, if the Ramsey allocations are feasible for the sustainable Markov problem, then they necessarily solve it. So consider the Ramsey allocations given the state variables $\left(M_{-1}, b_{-1}\right.$, $\left.B_{-1}\right)$. These allocations clearly satisfy the resource constraint and the implementability constraint in period 0 in the sustainable Markov problem. Given the values for the new state variables $\left(M_{0}, b_{0}, B_{0}\right)$ constructed as in the definition of time consistency, these state variables plus the continuation of the period 0 allocations clearly satisfy the remaining constraints of the sustainable Markov problem, namely, the implementability constraint in period 1, by construction, and the sustainability constraint, since using the same logic as that of period 0 it follows that

$$
V_{1}^{R}\left(M_{0}, b_{0}, B_{0}\right) \geq V_{1}\left(M_{0}, b_{0}, B_{0}\right)
$$

Q.E.D.

As a corollary to Propositions 6 and 7 and Lemmas 4 and 5, we conclude that if we make enough assumptions so that the first-order conditions are sufficient and the Friedman rule is optimal, then the Ramsey allocations are Markov sustainable allocations. These conditions include the assumptions that the utility function is separable and homothetic so that (18) holds; initial nominal government liabilities are period by period, so that (14) holds; the second-order conditions (22) hold; and $u_{c c t}+u_{c l t}<0$ and $u_{l l t}+u_{c l t}<0$ for all $t$, where $u$ is defined as before. 


\section{Notes}

${ }^{1}$ Notice that to arrive at our conclusion, it is crucial that $U_{l l t} \neq 0$ for some $t$ which together with concavity implies that $U_{l l t}<0$. (In the nonseparable case, considered in Proposition 4, the analogous condition is $U_{c l t}+U_{l l t}<0$.) If the utility function is linear in labor $l$, our result does not hold. With such linearity, real interest rates are exogenously given and then, with our setting of the nominal debt, the Ramsey problem is time consistent, regardless of whether the Friedman rule holds. Essentially, our setting of the nominal debt eliminates the nominal time consistency problem identified by Calvo (1978). Making the utility function linear eliminates the ability of the government to manipulate real interest rates and, hence, eliminates the real time consistency problem identified by Lucas and Stokey (1983), regardless of whether the Friedman rule is optimal. 


\section{References}

Auernheimer, Leonardo (1974): "The Honest Government's Guide to the Revenue from the Creation of Money," Journal of Political Economy, 82 (No. 3, May/June), 598-606.

Calvo, Guillermo A. (1978): "On the Time Consistency of Optimal Policy in a Monetary Economy," Econometrica, 46 (No. 6, November), 1411-28.

Calvo, Guillermo A., and Maurice Obstfeld (1990): "Time Consistency of Fiscal and Monetary Policy: A Comment," Econometrica, 58 (No. 5, September), 1245-47.

Chari, V. V., and Patrick J. Kehoe (1990): "Sustainable Plans," Journal of Political Economy, 98 (No. 4, August), 783-802.

(1993): "Sustainable Plans and Debt," Journal of Economic Theory, 61 (No. 2, December), 230-61.

Chari, V. V., Lawrence J. Christiano, and Patrick J. Kehoe (1996): "Optimality of the Friedman Rule in Economies with Distorting Taxes," Journal of Monetary Economics, 37 (Nos. 2-3, April), 203-23.

Correia, Isabel, and Pedro Teles (1999): "The Optimal Inflation Tax," Review of Economic Dynamics, 2 (No. 2, April), 325-46.

Friedman, Milton (1969): "The Optimum Quantity of Money," in The Optimum Quantity of Money and Other Essays, pp. 1-50. Chicago: Aldine.

Lucas, Robert E., Jr., and Nancy L. Stokey (1983): "Optimal Fiscal and Monetary Policy in an Economy without Capital," Journal of Monetary Economics, 12 (No. 1, July), 55-93.

Lucas, Robert E., Jr. (2000a): "Some Macroeconomics for the 21st Century," Journal of Economic Perspectives, 14 (No. 1, Winter), 159-68.

(2000b): "Inflation and Welfare," Econometrica, 68 (No. 2, March), 247-74.

Persson, Mats, Torsten Persson, and Lars E. O. Svensson (1987): "Time Consistency of Fiscal and Monetary Policy," Econometrica, 55 (No. 6, November), 1419-31.

(1989): "Time Consistency of Fiscal and Monetary Policy: A Reply," IIES Seminar Paper No. 427 (January).

Ramsey, Frank P. (1927): "A Contribution to the Theory of Taxation," Economic Journal, 37 (March), 47-61.

Stokey, Nancy L. (1991): "Credible Public Policy," Journal of Economic Dynamics and Control, 15 (No. 4, October), 627-56. 